
\title{
Nutraceutical Potential of Agri-Horticultural Wastes
}

\author{
Charu Gupta ${ }^{1 *}$, Dhan Prakash ${ }^{1}$ and Monica Azucena Nazareno ${ }^{2}$ \\ ${ }^{1}$ Amity Institute for Herbal Research \& Studies, Amity University UP, Noida, India \\ ${ }^{2}$ Laboratorio de Antioxidantes Procesos Oxidativos, Centro de Investigacin Transferencia de \\ Santiago del Estero (CITSE-CONICET), Universidad Nacional de Santiago del Estero (UNSE),Av. \\ Belgrano (S) 1912, 4200 - Santiago del Estero (Argentina)
}

Received: 4 August, 2017; Accepted: 8 September, 2017; Published: 13 September, 2017

*Corresponding author: Charu Gupta, Amity Institute for Herbal Research \& Studies, Amity University UP, Noida, India. Email: charumicro@gmail.com

\begin{abstract}
Fruits, vegetables, dairy and other food processing wastes are produced in large quantities in fields, farms, markets, processing industry sites and cause a major havoc in their disposal due to their high rate of biodegradation. Waste utilization from food processing industries is highly indispensable and challenging task all around the globe. Studies have proved that the agri-horticultural wastes are rich source of valuable phytochemicals and nutrients that can serve as a potential source of nutraceuticals and functional foods. They are also rich in some other secondary metabolites that can be beneficial as adjuvant in the management of several health care issues like ageing, hypertension, cancer, cardiovascular and other degenerative diseases. The full utilization of agri-horticultural produce is in demand all over the world to implement low-waste technology in their agribusiness. The waste obtained from food processing industries is extremely diverse due to the use of wide variety of fruits and vegetables, the broad range of processes and the multiplicity of the product. Agrihorticultural wastes are cost effective source of various phytonutrients that can play important protective role in human health from various ailments.
\end{abstract}

Keywords: Agri-horticultural residues; Diseases; Antioxidants; Nutraceutical; Functional foods

\section{Introduction}

As per the statistics reported by United Nations Environment Programme (UNEP) roughly one third of the food produced in the world for human consumption every year approximately 1.3 billion tons of food is lost or wasted. The amount of food lost or wasted every year is equivalent to more than half of the world's annual cereals crop (2.3 billion tons). The Food and Agriculture Organization of the United Nations (FAO) estimates that, each year, one-third of all food produced for human consumption in the world (around 1.3 billion tons) is lost or wasted. This includes $45 \%$ of all fruit and vegetables, $35 \%$ of fish and seafood, $30 \%$ of cereals, $20 \%$ of dairy products and $20 \%$ of meat [31].

Large amounts of food are still lost during the production process in developing countries, however, due to lack of infrastructure and poor equipment. Wastage at the consumption stage in these countries, meanwhile, is drastically less than developed nations. India, the world's second largest producer of fruits and vegetables, throws away fresh produce worth Rs.13,300 crores every year because of the country's lack of adequate cold storage facilities and refrigerated transport [58].
Food processing wastes are the end products of various food processing industries that have not been recycled or used for other purposes. These agri-horticultural wastes constitute a big problem in municipal landfills due to their high rate of biodegradability. In other words, they are the non-product flows of raw materials whose economic values are less than the cost of their collection and recovery; and therefore discarded as wastes. Several scientific studies have shown that these wastes could be considered as valuable by-products in the form of phytochemicals and nutraceuticals if they are treated scientifically and technically. Numerous researchers have worked on generation of phytochemicals, antioxidants, dietary-fiber, food ingredients like pectin, natural colour, vitamins, antibiotics and proteases apart from ethanol or biogas from waste generated from fruits, vegetables, cereals, pulses milling, coffee processing units [45].

Fruits and vegetables are an important part of a balanced diet. Besides their delicious taste and flavor, they are known to reduce risk of several chronic diseases. Fruits and vegetables contain significant amounts of phytoconstituents which are negatively associated with the morbidity and mortality from cerebrovascular, cardiovascular and certain types of cancers $[4,30,44]$. Foods are generally consumed for their nutritive value and bioactive compounds [9]. Fruits and vegetables wastes and their by-products are formed in very high amounts during industrial processing and hence represent a serious problem, as they exert harmful impact on environment. So they need to be managed or they can be utilized [12]. The utilization of by-products or wastes from industrial processing of fruit and vegetables, i.e. apple, currant, citrus fruit, carrot, tomato, melon, grapes or spinach pomace is convenient and cost-effective and enables rational management of trouble some wastes. Different components having activities like anti-microbial, antioxidant, anti-proliferative, anti-inflammatory, etc. have been isolated from different peels.

There are many studies that proved that the most abundant by-products of minimal processing of fresh-cut fruit and vegetable are peel and seed and those are reported to contain high amounts of phenolic compounds with antioxidant and antimicrobial properties. Several studies have shown that the content of phytochemical compounds is higher in peel and seeds with respect to the edible tissue [20]. The total phenolic and flavonoid contents were higher in the by-products as compared 
to the final products, being more pronounced in mango seeds and peels. Gorinstein, et al. found that the total phenolic compounds in the peels of lemons, oranges, and grapefruits were 15\% higher than that of the pulp of these fruits [17]. Peels from apples, peaches, pears as well as yellow and white flesh nectarines were found to contain twice the amount of total phenolic compounds as that contained in fruit pulp. Apple peels were found to contain up to $3300 \mathrm{mg} / 100 \mathrm{~g}$ of dry weight of phenolic compounds. Pomegranate peels contain $249.4 \mathrm{mg} / \mathrm{g}$ of phenolic compounds as compared to only $24.4 \mathrm{mg} / \mathrm{g}$ phenolic compounds found in the pulp of pomegranates. Total phenolic compounds of seeds of several fruits, such as mangos, longans, avocados and jackfruits, were higher than that of the edible product; grape seeds and skins, the byproducts of grape juice and white wine production, are also sources of several phenolic compounds, particularly mono, oligo, and polymeric pro-anthocyanidins $[47,48]$. The peels and seeds of tomatoes are richer sources of phenolic compounds than the pulp of the tomatoes. The peel byproduct of tomato has significantly higher levels of total phenolic compounds, total flavonoids, lycopene, ascorbic acid, and antioxidant activity as compared with the pulp and seeds [15].

\section{Phytochemicals of Nutraceutical Importance from Agri-Horticultural Wastes}

Agri-horticultural waste are cost effective natural sources of various phytonutrients that may be classified as phenols (tannins, lignins, anthocyanins, isoflavones, flavonones, flavanoids), isoprenoid derivatives (terpenoids, carotenoids, saponins, tocotrienols, tocopherols, terpenes), carbohydrate derivatives (ascorbic acid, oligosaccharides, non-starch polysaccharides), fatty acid and structural lipids (n-3 PUFA, CLA, MUFA, sphingolipids, lecithins), amino acid derivatives, microbes (probiotics, prebiotics) and minerals [46].

Phytonutrients play important role in human health as antioxidants, antibacterial, antifungal, anti-inflammatory, antiallergic, antispasmodic, chemo-preventive, hepato-protective, hypolipidemic, neuro-protective, hypotensive agents, and help in preventing aging, diabetes, osteoporosis, cancer and heart diseases, induce apoptosis, diuretic, CNS stimulant, analgesic, protects from UVB-induced carcinogenesis, immuno-modulator and carminative [21].

Vegetables and some fruits yield 25 to $30 \%$ of non-edible products [3]. The failure or inability to salvage and reuse such materials economically results in the unnecessary waste and depletion of natural resources [10]. The entire tissue of fruits and vegetables are rich in bio-active compounds, such as phenolic compounds, carotenoids, flavonoids, anthocyanins, vitamins and in most cases the waste by-products can present similar or even higher contents of antioxidant and antimicrobial compounds [7].

The waste materials such as peels, seeds and stones produced from the fruit and vegetable processing unit can be successfully used as a source of phytochemicals with significant importance in nutraceuticals. Higher amount of phenolic compounds and ascorbic acids has been reported in the peel than in pulp [18] and in green form than in ripe [13] for most of the fruits. The majority of fruit peels exhibited 2 to 27 fold higher antioxidant activity than the fruit pulp [19]. Edible pulp of bananas (Musa paradisiaca) contains $232 \mathrm{mg} / 100 \mathrm{~g}$ of dry weight phenolic compounds, this amount is about $25 \%$ of that present in the peel [52]. Residues from star fruit (Averrhoa carambola L.), grape pomace (Vitis sp.), citrus fruits peel (Citrus sp.), by products from pomegranate (Punica granatum L.) and banana peel (Musa acuminata Colla $A A A$ ) have been evaluated as inexpensive sources of antioxidants $[49,28,59,51,16]$.

The dry crude extracts of agro-industrial wastes such as peels of Aloe vera, Cucumis sativus, Citrus paradisi, Citrus aurantium, Punica granatum and leaves of Olive europaea were evaluated for their antimicrobial and antifungal activities by and all the extracts inhibited the growth of bacteria like E. coli and $S$. aureus and fungal pathogens like A. niger and P. digitatum [32].

\section{Commercially Important Products from Fruits and Vegetables Waste}

\section{Dietary Fibers}

Dietary Fibers (DF) play an important role in the prevention and cure of diabetes, obesity, atherosclerosis, heart diseases, colon cancer and colorectal cancer. Hemicellulose and pectin were found to have a remarkable capability of binding metal ions.

Investigations into fruit and vegetable pomace have revealed a Neutral Dietary Fiber (NDF) content of 18 to $87 \%$ dry matter (DM), and an Acid Dietary Fiber (ADF) content ranging between 16 and $57 \%$ DM. The NDF content in the fruit pomace varies from $24.20 \mathrm{~g} / 100 \mathrm{~g}$ DM to $87.48 \mathrm{~g} / 100 \mathrm{~g} \mathrm{DM}$; and that in the vegetable pomace from $18.05 \mathrm{~g} / 100 \mathrm{~g}$ DM to $34.76 \mathrm{~g} / 100 \mathrm{~g}$ DM. The ADF content is very high in the fruit pomace (19.81 to $57.24 \mathrm{~g} / 100 \mathrm{~g}$ $\mathrm{DM})$ and slightly lower in the vegetable pomace $(16.02 \mathrm{~g} / 100 \mathrm{~g}$ DM to $29.33 \mathrm{~g} / 100 \mathrm{~g}$ DM).

Compared to the majority of fruit pomace samples, the vegetable pomace samples showed slightly lower contents of particular DF fractions. The DF content was higher in the red cabbage pomace samples than in the pomace samples of 'Black' and 'Dolanka' carrots (NDF: 34.76 g/100 g DM; ADF: 29.33 g/100 g DM); cellulose and hemicellulose content amounting to 15.20 g/100 g DM and $14.13 \mathrm{~g} / 100 \mathrm{~g} \mathrm{DM}$, respectively [42].

\section{Polysaccharides}

Polysaccharides extracted from mulberry leaves show antioxidant properties (tested as DPPH-scavenging activity) and good anti-bacterial effects against some common pathogens such as Bacillus subtilis, E. coli and Staphylococcus aureus [57]. Polysaccharides extracted from plants such as Aloe barbadensis, Lentinus edodes, Ganoderma lucidum, Coriolus versicolor, resulted to exert both anti-genotoxic and anti-tumor promoting activities in vitro models and thus might be considered as potential cancer chemo-preventive substances [25]. The biological properties of polysaccharides from tomato, granadilla and lemon wastes indicate their role of this biopolymer in the control of oxidative stress and/or inflammation process. 


\section{Pectin}

Citrus wastes are rich source of essential oils, pectin and a variety of by-products. The failure or inability to salvage and reuse such materials economically results in the unnecessary waste and depletion of natural resources. Apple and citrus wastes are traditionally the main sources of commercial pectin [55]. Citrus fruits are particularly rich in pectin ranging from 20 to $30 \%$ of dry matter waste and the large quantities of citrus wastes generated by the fruit juice industry represent one of the most important raw materials for the production of commercial pectin. Another interesting example of citrus waste biomass is represented by bergamot, Citrus bergamia residues. Bergamot is used in Italy mostly for the extraction of its essential oil, obtained by wash-scraping the fruit. The annual Italian production of bergamot amounts to 25,000 tons and peel is an under-utilized by-product of the essential oil and juice processing industry that likewise other citrus waste peels still contains exploitable biopolymers such as pectin.

\section{Proteases}

Wastes like potato, pumpkin, cauliflower, cabbage and brinjal have been employed for production of protease by solid state fermentation using Aspergillus niger. Estimation of specific activities for individual substrates conferred the highest upon pumpkinwith13.44U mg protein/ml, with comparable results obtained for cauliflower and cabbage. This study presents a novel and economical approach for the bioconversion of vegetable wastes for the production of protease that is industrially significant [53].

\section{Single Cell Proteins}

Mondel et al. investigated the production of Saccharomyces cerevisiae in cucumber and orange peels and found that higher amount of crude protein $(53.4 \%)$ was obtained from cucumber peels [35]. Cucumber peels contained higher amount of available carbohydrates and minerals that have favorably affected yeast biomass production. Though orange peel also contained high concentration of carbohydrates but supported less biomass production. This may be due to the less mineral content in orange peels $(3.55 \%)$ than that of present in cucumber peels $(6.96 \%)$ and hence resulted in lower growth of yeast biomass.

The waste materials such as peels, seeds and stones produced by the fruit and vegetable processing can also be successfully used as a source of phytochemicals and antioxidants.

\section{Mango fruit peel and seed kernel}

During processing of mango, peel is a major by-product that contributes about $15-20 \%$ of the fruit. Peel is not currently utilized for any commercial purpose and is discarded as a waste pollution. Studies have shown that mango peel contain phytochemicals, such as polyphenols, carotenoids, vitamin E, dietary fibre and vitamin C with good antioxidant properties [33].

Mango seed kernels have been found to contain considerable amount of total phenolic compounds, total lipid, unsaponifiable matter and a low amount of crude protein, but the quality of protein was good as it is rich in all essential amino acids. Proximate composition, amino acid profile and anti-nutrients contents of Nigerian mango seed were investigated. Mango seed contains $10.06 \%$ crude protein, $14.80 \%$ oil, $2.62 \%$ ash, $2.40 \%$ crude fibre, $70.12 \%$ carbohydrate and energy content 453.92 $\mathrm{KJ} / 100 \mathrm{~g}$. Mango seed is very rich in glutamate $(13.00 \mathrm{~g} / 100 \mathrm{~g}$ of protein) while methionine has the lowest value $(1.04 \mathrm{~g} / 100$ $\mathrm{g}$ of protein). Eight phenolic compounds have been identified in mango seed extract amongst which tannin and vanillin were in highest amounts [42]. On phytochemical analysis acetone extract of mango peel was found to contain polyphenols, anthocyanins and carotenoids [2]. In another study, the free radical scavenging activities of mango flesh and peel extracts were evaluated by electron spin resonance and it was found that mango peel extract exhibited stronger free radical scavenging ability on 1,1-diphenyl2-picrylhydrazyl and alkyl radicals than mango flesh extract without any relation to its ripeness [27].

\section{Apple pomace}

Apple pomace is the by-product of processing for the recovery of apple juice and amounts to up to $25-35 \%$ of the processed fruit. Although it is conventionally used as an animal feed, the production of pectin is considered to be the most reasonable utilization approach from both economic and ecological points of view. Pectin consists of $10-15 \%$ of apple pomace, on a dry weight basis and has more superior gelling properties than citrus pectin but presents a brown hue that may limit its incorporation into light-colour foods [53]. It is also a rich source of polyphenols which are predominantly localized in the peels, minerals and dietary fibre. Major compounds isolated and identified include catechins, hydroxyl-cinnamates, phloretin glycosides, quercetin glycosides, and procyanidins. Apple pomace contains polyphenols like epicatechin, its dimer (procyanidin $\mathrm{B}_{2}$ ), trimer, tetramer and oligomer, quercetin glycosides, chlorogenic acid, phloridzin and 3-hydroxy phloridzin. All these compounds showed strong antioxidant activities, and their DPPH scavenging activities were 2-3 times and superoxide anion radical scavenging activities were 10-30 times better than those of the antioxidant vitamins $C$ and E. The total phenolics, total flavonoids, total flavan-3-ols and some individual phenolic compounds contributed significantly to the antiradical activities of apple pomace [42]. Furthermore, tumour-cell proliferation has strongly inhibited in vitro by apple extracts, and these effects have been attributed to phenolic acids and flavonoids [43].

\section{Grapes}

Grapes (Vitis sp., family Vitaceae) pomace represents approximately $20 \%$ of the weight of grapes. Its composition varies considerably, depending on grape variety and technology of wine making. However, wine making leads to the generation of large quantities of wastes (around 5-9 million tonnes per year, worldwide), which considerably increase the Chemical Oxygen 
Demand (COD) and the Biochemical Oxygen Demand (BOD) due to a high pollution load. Grape pomace is considered as a valuable source of phenolic compounds which could be recovered as functional food ingredients. The seeds constitute a considerable proportion of the pomace, amounting to $38-52 \%$ on a dry matter basis. Their oil is rich in unsaturated fatty acids, linoleic acid in particular. Grape seed oil is mainly produced in Italy, France and Spain; however, the demand for this oil has also increased in the rest of Europe. Apart from being a rich source of highvalue fatty oil, grape seeds have also been appreciated because of their content of phenolic compounds such as gallic acid, catechin and epicatechin, and a wide variety of procyanidins. Catechin, epicatechin, epicatechin gallate and epigallocatechin are the major constitutive units of grape skin tannins. Also, a great range of products such as ethanol, tartrates, citric acid, grape seed oil, hydrocolloids, and dietary fibre are recovered from grape pomace [43]. Hot water extracts of Grape Skin Pulp Extract (GSPE) can serve as a good substrate for fermentation with Aureobasidium pullulans (a yeast like fungus) for the production of pullulan (-glucan). Pullulan is a commercially important polysaccharide with many industrial applications. Fermentation parameters for pullulan production from Grape Skin Pulp Extract (GSPE) have been developed [26].

The high efficiency of natural phenolic extracts obtained from grape seeds as potent antioxidants was confirmed, by the fact which encourages the prospect of their commercialization as natural powerful antioxidants in foods in order to increase the shelf life of food by preventing lipid peroxidation and protecting from oxidative damage. Many of the grape seed products are commercially available. Recent reports indicate a wide range of biological activities, e.g. radio protective effects, prevention of cataract, anti-hyperglycemic effects, enhancement of postprandial lipemia, and modulation of expression of antioxidant enzyme systems, inhibition of protein kinase activity of the epidermal growth factor receptor, protective effects against oxidative damage in mouse brain cells, and anti-inflammatory effects [37]. Pomace of red grapes (Vitis vinifera) is also the richest natural source of resveratrol which has anti-oxidant properties. It is a phytoestrogen that exert neuro-protective effects as well as beneficial effects on the cardiovascular system, osteoporosis and cancer [22].

\section{Citrus Fruits}

The family of citrus fruits consists of Oranges, Kinnow, Khatta, Lime, Lemon, Grapefruit, Malta, Sweet orange etc. The large quantities of processed citrus fruits result in large amounts of byproducts.

Citrus peel, remaining after juice extraction, is the primary waste fraction amounting to almost $50 \%$ of the fruit mass. It is processed to dried pulp cattle feed and molasses, the latter being incorporated into the cattle feed or fermented for the production of valuable products like biogas, ethanol, citric acid, various enzymes, volatile flavouring compounds, fatty acids and microbial biomass. Pectin is also produced from the peel by acid extraction, dietary fibres by mechanical processing, while the recovery of flavonoids and carotenoids are new potential applications [53].

Citrus by-products could be major sources of phenolic compounds. The peels, in particular, are an abundant source of natural flavonoids, and contain higher amount of phenolic compared to the edible portions. It has been reported that the contents of total phenols in peels of lemons, oranges, and grapefruit were $15 \%$ higher than those in the peeled fruits. Flavonoids in citrus are a major class of secondary metabolites. The peel contains the highest amount of flavonoids than other parts and those flavonoids present in citrus fruits belong to six peculiar classes according to their structure. They are flavones, flavanones, flavonols, lavones, anthocyanidins and flavanols. Flavonoids from citrus have been extensively studied for antioxidative, anti-cancer, antiviral and anti-inflammatory activities. Recent studies suggested that citrus fruits possess another health benefit phytochemicals called limonoids, highly oxygenated tri-terpenoid. The limonoid aglycones are responsible for the development of delayed bitterness in citrus. Currently limonoids are under investigation for a wide variety of therapeutic effects such as antiviral, antifungal, antibacterial, antineoplastic and antimalarial. Certain limonoids are insecticides such as azadirachtin from the neem tree. Most recently several limonoid aglycones and a mixture of limonoid glucosides were administered in vitro to estrogen dependent and estrogen independent human breast cancer cell lines [17,42].

\section{Pineapple}

It is anticipated that both the discarded fruits as well as the waste material of pineapple can be utilized for further industrial processes like fermentation, bioactive component extraction, etc. In this regard, several efforts have been made in order to utilize pineapple wastes obtained from different sources. The wastes from pineapple canneries have been used as the substrate for bromelain, organic acids, ethanol, etc. since these are potential source of sugars, vitamins and growth factors. Several studies have been carried out since decades on trying to explore the possibility of using these wastes. In past, sugar has been obtained from pineapple effluent by ion exchange and further use it in syrup for canning pineapple slices. Pineapple wastes can also be used for the production of organic acids such as citric acid, lactic acid and ferulic acid [53].

Pineapple fruit residues have been used as an effective biosorbent to remove toxic metals like mercury, lead, cadmium, copper, zinc and nickel. Bromelain is the most valuable component from the pineapple waste. It is a crude extract of pineapple that contains, among other components, various closely related proteinases, and demonstrating, in vitro and in vivo, antiedematous, anti-inflammatory, antithrombotic, fibrinolytic activities and has potential as an anticancer agent. It is also used in food industry as meat tenderizer and as a dietary supplement. Crude commercial bromelain from pineapple stem has been 
purified by successive use of ion exchange chromatography, gel filtration, and ammonium sulfate fractionation.

Organisms like Saccharomyces cerevisiae, and Zymomonas mobilis ATCC 10988 were capable of producing about $8 \%$ ethanol from pineapple waste in $48 \mathrm{~h}$ after pretreating with enzymes cellulase and hemi-cellulase. Fruit phenolic content was found as $40.4 \mathrm{mg} / 100 \mathrm{~g}$ as Gallic Acid Equivalent (GAE) with the highest ethyl acetate bound phenolic, 2.58 as chlorogenic acid equivalent, while juice had $358 \mathrm{mg} / \mathrm{L}$ as gallic acid equivalent [37]. Phenolic antioxidants from the wastes are also found to be in higher amounts. The methanol extraction yield and total phenolic contents of pineapple residue (pulp, seeds and peel) were $30.2 \%$ and $10 \mathrm{mg} / \mathrm{g}$ GAE. They co-related the antioxidant activities of the phenolic compounds using DPPH free radical scavenging activity and superoxide anion scavenging activity. Phenolic such as myricetin, salicyclic acid, tannic acid, trans-cinnamic acid and p-coumaric acid has been identified in the high dietary fiber powder form pineapple shell. FRAP value for pineapple peel has been reported as $2.01 \mathrm{mmol} / 100 \mathrm{~g}$ wet weight. Potent fungicides like cinnamic, p-coumaric and ferulic acids have been produced from pineapple stems residues. Phenolic antioxidant from pineapple waste may be converted to more potent compounds by cytochrome P4502C9 is ozyme in-vitro. Anti-inflammatory and anti-diabetic potential of pineapple stem waste has also been reported [56,42].

\section{Pomegranate (Punica granatum)}

The pomegranate tree is native to Asia and Middle East countries. Pomegranate fruit has antioxidant compounds such as tannins and flavonoids. These phenolic compounds are responsible for its exceptional healing qualities [1]. The antimicrobial activity of various extracts prepared from pomegranate fruit peels were evaluated and it was found that $80 \%$ methanolic extract of peels was a potent inhibitor for Yersinia enterocolitica, Listeria monocytogenes, Staphylococcus aureus and Escherichia coli. This is due to the presence of active inhibitors in peels including phenolics and flavonoids as potent constituents $[5,40]$.

\section{Banana (Musa paradisiaca)}

Banana is one of the most popular fruits of world [34]. Its peel is rich in dietary fiber, proteins, essential amino acids, polyunsaturated fatty acids and potassium [16]. In a study, the antioxidant activities of the extracts obtained from fresh green and yellow banana peel fruits were evaluated by using the thiocyanate method, $\beta$-carotene bleaching method and 1,1-diphenyl-2picrylhydrazyl free radical elimination method. The green peel displayed high antimicrobial and antioxidant activity. Antioxidant activity of water extracts was more pronounced and comparable to those of synthetic commercial antioxidants such as Butylated Hydroxyanisole (BHA) and Butylated Hydroxytoluene (BHT). Amongst all isolated components succinic acid, $\beta$-sitosterol, palmitic acid, malic acid, 12-hydroxystrearic acid, glycoside, d-malic and 12-hydroxystrearic acid were the most active against all Gram negative and positive bacterial species tested $[34,40]$.

\section{Indian blackberry (Syzygium cumini)}

Syzygium cumini though is native to tropical America and Australia, but is available in Indian plains ranging from the Himalayas to southern India [8]. The antioxidant activity of the fruit peel has been analyzed using different assays such as DPPH radical-scavenging assay. A significant correlation was found between concentration of the extract and percentage inhibition of free radicals as well as percentage inhibition of lipid peroxidation. The antioxidant property of the fruit peel was partially from the antioxidant vitamins, phenols or tannins and anthocyanins present in the fruit $[9,40]$.

\section{Ridge Gourd (Luffa cylindrica)}

Luffa cylindrica is a sub-tropical plant commonly called sponge gourd, loofa, vegetable sponge, bath sponge or dish cloth gourd belonging to family Cucurbitaceae. The anti-oxidative potential of peel extract of Luffa cylindrica was investigated and the results demonstrated a dose dependent inhibition in all the three i.e. FeSO4, $\mathrm{H} 2 \mathrm{O} 2$ and $\mathrm{CCl} 4$ induced hepatic lipid peroxidation. It was observed that polyphenols and flavonoids of Luffa cylindrica peels could be inhibiting lipid peroxidation $[11,40]$.

\section{Potato (Solanum tuberosum)}

Potato peels have shown antioxidant properties. In an experiment aqueous extract of freeze dried. Potato-peel powder demonstrated strong inhibitory activity toward lipid peroxidation of rat liver homogenate. Potato peel extract also demonstrated a considerable antioxidant activity in the DPPH radical assay system. It also showed antioxidant activity in multiple systems such as superoxide scavenging ability, reducing power and also ferrous ion chelating potency. These results established the antioxidant potency of freeze-dried extract of potato peel $[50,40]$.

\section{By Products from Cereals, Pulses and Oilseeds Processing}

\section{Rice Husk and Rice Bran}

Rice husk is the largest product of the rice milling industry comprising 20 to 25 per cent of paddy. Paddy yields about 5 to $7 \%$ bran. The availability of rice husk is about $15 \mathrm{Mt}$ annually. A typical paddy husk sample contains $42.6 \%$ cellulose, $20.1 \%$ lignin, $18.6 \%$ pentosans and $18.7 \%$ ash. It is exploited for production of rice bran oil [29,39].

\section{Coffee Industry By-products}

Coffee production worldwide is about 105 million tons annually. Industrial processing of coffee is done by removing shell and mucilaginous part from cherries. Coffee is subjected to puling, washing, drying, curing, roasting, and brewing and during the process; various byproducts such as coffee pulp, cherry husk, parchment husk, silver skin and spent waste are obtained. Coffee pulp, husk, silver skin, and spent coffee were subjected to extraction of phenolics. Silver skin was found to 
have highest phenolics (25\%), followed by spent waste (19\%) and cherry husk (17\%) after pre-treatment with viscozyme. The bioactive conserves prepared from coffee by-products possessed 65 to $70 \%$ antioxidant activity in terms of chlorogenic acid. The antioxidant activity of the by-products was found to be 1.5 to 2.0 mmol trolox/100g [36].

\section{Pulse Milling Waste}

Agro-wastes are basically composed of cellulose and lignin along with other components which carries a variety of functional groups. They have the capability of complexing heavy metal ions which facilitate their removal by adsorption. The processing of agro-waste for their modification into carbon form is needed as in this form the agro-waste possesses high porosity and large surface area making it more effective for metal adsorption process [14,38].

Pigeon pea (Cajanus cajan) husk which is about $8 \%$ of the pulse grain and is the low cost by product or waste of pulse processing industry. The husk of pigeon pea is reported to contain about $5.6 \%$ crude protein, $0.3 \%$ fat, $31.9 \%$ crude fiber, $3.5 \%$ ash and $58.7 \%$ carbohydrates and possess potential to be used as metal adsorbent. The washed and dried pigeon pea husk is carbonized in air tight container at $500^{\circ} \mathrm{C}$ for $1 \mathrm{hr}$ to get its carbon form possessing adsorption property [41]. In a study, the green gram and bengal gram husk were used as a substrate for production of single cell protein in maltose enriched medium $(7.7 \mathrm{mg})$. It attained maximum yield of $9.2 \mathrm{mg}$ in 6 -10days of fermentation [6].

\section{Dairy Industry waste}

Milk whey commonly known as cheese whey or lactoserum is a by-product of cheese or casein in the dairy industry and contains usually high levels of lactose, low levels of nitrogenous compounds, protein, salts, lactic acid and small amounts of vitamins and minerals. Milk whey contains several unique components like immunoglobulins (Igs), lactoferrin (Lf), lactoperoxidase (Lp), glycomacropeptide (GMP) and sphingolipids that possess some important antimicrobial and antiviral properties. Some whey components possess anticancer properties such as sphingomyelin have potential to inhibit colon cancer. IgGs, Lp and Lf concentrated from whey participates in host immunity. There are some wheyderived carbohydrate components that possess prebiotic activity. Lactose support lactic acid bacteria (such as Bifidobacteria and Lactobacilli). Stallic acids, an oligosaccharide in whey, are typically attached to proteins, possess prebiotic properties. Whey proteins are unique in their ability to optimize a number of aspects of the immune system, primarily by boosting glutathione (GSH) levels in various tissues. GSH, the centerpiece of the body's antioxidant defense system, protects cells against free radical damage, pollution, toxins, infection and UV exposure. GSH levels are typically depressed in individuals with cancer, HIV, chronic fatigue syndrome and other immune-compromising conditions. The sulphur containing amino-acids (cysteine and methionine) are also found in high levels in whey protein $[20,54,23,24]$.

\section{Conclusion}

From the foregoing, it can be safely concluded that agrihorticultural wastes has tremendous potential to be used as source of valuable phytochemicals of nutraceutical importance. The utilization of the waste material could add significant value to the food processing chains thus improving economic performance and decreasing disposal problems. It is important to promote the use of more fruit and vegetable waste to obtain by-products with functional properties and health benefits. Thus food manufacturers should also invest in specialized secondary industry to utilize the agri-horticultural residues. Efforts are needed to develop new technologies to reduce, recycling and reuse wastes. This can only be achieved if food residues are considered as complementary resources rather than as undesirable wastes.

\section{Acknowledgement}

The authors greatly acknowledge the funding agencies MinCyT-Argentina \& DST-India for their financial support \& help.

The authors are grateful to Dr. Ashok K. Chauhan, Founder President and Mr. Atul Chauhan, Chancellor, Amity University UP, Noida, India for the encouragement, research facilities and financial support.

\section{References}

1. Adhami VM, Khan N, Mukhtar H. Cancer Chemoprevention by Pomegranate: Laboratory and Clinical Evidence. Nutr Cancer. 2009;61(6):811-815. doi:10.1080/01635580903285064

2. Ajila CM, Naidu KA, Bhat SG, Prasada RUJS. Bioactive compounds and antioxidant potential of mango peel extract. Food Chemistry. 2007;105(3):982-988.

3. Ajila CM, Aalami M, Leelavathi K, Rao UJSP. Mango peel powder: a potential source of antioxidant and dietary fibre in macaroni preparations. Innovative Food Sci Emerging. 2010;11(1):219-224.

4. Alesiani D, Canini A, Abrosca BD, DellaGreca M, Fiorentino A, Mastellone $\mathrm{C}$, et al. Antioxidant and anti-proliferative activities of phytochemicals from Quince (Cydonia vulgaris) peels. Food Chemistry. 2010;118(2):199-207.

5. Al-Zoreky NS. Antimicrobial activity of pomegranate (Punica granatum L.) fruit peels. Int J Food Microbiol. 2009;134(3):244-248. doi: 10.1016/j.ijfoodmicro.2009.07.002

6. Anbuselvi S, Mahalanobis S, Jha M. Optimizing the production of Single Cell Proteins using Bengal gram husk and pigeon pea husk using yeast. Int J Pharm Sci Rev Res. 2014;28(1):188-190.

7. Ayala-Zavala JF, Wang SY, Wang CY, Gonzalez-Aguilar GA. Effect of storage temperatures on antioxidant capacity and aroma compounds in strawberry fruit. Lebensm Wiss u Technol. 2004;37:687-695.

8. Ayyanar M, Babu-Subash P. Syzygium cumini (L.) Skeels: A review of its phytochemical constituents and traditional uses. Asian Pac J Trop Biomed. 2012;2(3):240-246. doi: 10.1016/S2221-1691(12)600501

9. Banerjee A, Dasgupta N, Bratati De. In vitro study of antioxidant activity of Syzygium cumini fruit. Food Chemistry. 2005;90(4):727733. 
10. Bhalerao SD, Mulmuley GV, Ananthakrishna SM, Potty VH. Waste and waste water management in food industry: Fruit and vegetable processing. Indian Food Packer. 1989;43:5-11.

11. Dixit Y, Anand Kar. Antioxidative activity of some vegetable peels determined in vitro by inducing liver lipid peroxidation. Food Research International. 2009;42(9):1351-1354.

12. Duda-Chodak A, Tarko T. Antioxidant properties of different fruit seeds and peels Acta Sci Pol Technol Aliment. 2007;6(3):29-36.

13. Fatemeh SR, Saifullah R, Abbas FMA, Azhar ME. Total phenolics, flavonoids and antioxidant activity of banana pulp and peel flours: influence of variety and stage of ripeness. International Food Research Journal.2012;19(3):1041-1046.

14. Finkenstadt VL. Natural polysaccharides as electroactive polymers Appl Microbiol Biotechnol. 2005;67(6):735-745.

15. George B, Kaur C, Khurdiya DS, Kapoor HC. Antioxidants in tomato (Lycopersium esculentum) as a function of genotype. Food Chemistry. 2004;84(1):45-51.

16. González-Montelongo R, Lobo MG, González M. Antioxidant activity in banana peel extracts: Testing extraction conditions and related bioactive compounds. Food Chemistry. 2010;119:1030-1039.

17. Gorinstein, Martin-Belloso O, Park YS, Haruenkit R, Lojek A, Ciz M, et al. Comparison of some biochemical characteristics of different citrus fruits. Food Chemistry. 2001;74(3):309-315.

18. Goulas V, Manganaris GA. Exploring the phytochemical content and the antioxidant potential of citrus fruits grown in Cyprus. Food Chemistry. 2012;131:39-47.

19. Guo C, Yang J, Wei J, Li Y, Xu J, Jaing Y. Antioxidant activities of peel, pulp and seed fractions of common fruits as determined by FRAP assay. Nutrition Research. 2003;23:1719-1726.

20. Gupta C, Prakash D. Therapeutic Potential of Milk Whey. Beverages. 2017;3(3):31

21. Gupta C, Prakash D. Phytonutrients as therapeutic agents. J Complement Integr Med. 2014;11(3):151-169.

22. Gupta, C., Sharma, G. and Chan, D. Resveratrol: A chemo-preventative agent with diverse applications. In: Phytochemicals of Nutraceutical Importance. CABI International Publishers, UK; 2014. p. 47-60.

23. Gupta C, Prakash D, Garg AP, Gupta S. Whey Proteins: A novel source of Bioceuticals. Middle East Journal of Scientific Research. 2012;12(3):365-375.

24. Gupta C, Prakash D, Gupta S. Antioxidant potential of some Agrihorticultural waste. International Food Research Journal. 2017; 24(3):1156-1159.

25. Hyung SK, Kacew S, Mu Lee B. In vitro chemopreventive effects of plant polysaccharides (Aloe barbadensis Miller, Lentinus edodes, Ganoderma lucidum and Coriolus versicolor). Carcinogenesis.1999;20(8):1637-1640.

26. Israilides, CJ, Arapoglou D, Christopoulou N, Varzakas T. Recycling of grape skin pulp wastes (gspw) for the production of pullulan. In Proceedings of the International Biotechnology Conference, Patras, Greece, 2006;p.180.

27. Kim H, Moon JY, Kim H, Lee DS, Cho M, Choi HK, et al. Antioxidant and antiproliferative activities of mango (Mangifera indica L.) flesh and peel. Food Chemistry.2010;121:429-436
28. Lafka TI, Sinanoglou V, Lazos ES. On the extraction and antioxidant activity of phenolic compounds from winery wastes. Food Chemistry.2007;104(3):1206-1214.

29. Lakshmi NB, Suneetha JW, Maheswari KU, Kumari BA, Prabhakar NB. Antioxidant potential of rice bran and vegetable waste powders incorporated extrudates. The Pharma Innovation Journal; 2017;6(4):12-16.

30. Li Y, Guo C, Yang J, Wei J, Xu J, Cheng S. Evaluation of antioxidant properties of pomegranate peel extract in comparison with pomegranate pulp extract. Food Chemistry. 2006;96(2):254-260.

31. Lipinski B, Hanson C, Lomax J, Kitinoja L, Waite R, Searchinger T. Reducing Food Loss and Waste. World Resources Institute, Washington, DC. 2013.

32. Lutfullah G, Tila H, Hussain A, Ali Khan A. Evaluation of plants extracts for proximate chemical composition, antimicrobial and antifungal activities. American-Eurasian Journal of Agricultural \& Environmental Sciences. 2014;14:964-970.

33. Maisuthisakul P, Gordon MH. Antioxidant and tyrosinase inhibitory activity of mango seed kernel by product. Food Chemistry. 2009;117(2):332-341.

34. Mokbel MS, Hashinaga F. Antibacterial and Antioxidant Activities of Banana (Musa, AAA cv. Cavendish) Fruits Peel. American Journal of Biochemistry and Biotechnology. 2005;1(3):125-131.

35. Mondal AK, Sengupta S, Bhowal J, Bhattacharya DK. Utilization of Fruit Wastes in Producing Single Cell Protein. International Journal of Science, Environment and Technology. 2012;1(5):430-438.

36. Murthy PS, Naidu MM. Recovery of Phenolic antioxidants and functional compounds from Coffee industry by-products. Food and Bioprocess Technology. 2012;5(3):897-903.

37. Nawirska A, Uklanska C. Waste Products from Fruit and Vegetable Processing as Potential Sources for Food Enrichment in Dietary Fibre. Acta Sci Pol Technol Aliment. 2008;7(2):35-42.

38. Onipe OO, Jideani AIO, Beswa D. Composition and functionality of wheat bran and its application in some cereal food products. International Journal of Food Science and Technology. 2015;50(12):2509-2518.

39. Pal M, Kumar M, Gupta GR, Dwivedi KN. Utilization of Unused Bio-Waste for Agricultural Production - A Review. Plant Archives. 2014;14(1):597-604.

40. Parashar S, Sharma H, Garg M. Antimicrobial and Antioxidant activities of fruits and vegetable peels: A review. Journal of Pharmacognosy and Phytochemistry. 2014;3(1):160-164.

41. Parate VR, Talib MI. Study of Metal Adsorbent Prepared from Tur Dal (Cajanus cajan) Husk: A Value Addition to Agro-waste. IOSR Journal of Environmental Science, Toxicology and Food Technology. 2014;8(9):43-54.

42. Shalini Gaur Rudra, Jyoti Nishad, Neetu Jakhar, Charanjit Kaur. Food Industry waste: Mine of Nutraceuticals. International Journal of Science, Environment \& Technology. 2015;4(1):205-229.

43. Russ W, Meyer-Pittroff R. Utilizing Waste Products from the Food Production and Processing Industries. Crit Rev Food Sci Nutr. 2004;44(1):57-62. 
44. Sadek ES, Makris DP, Kefalas P. Polyphenolic Composition and Antioxidant Characteristics of Kumquat (Fortunella margarita) Peel Fractions. Plant Foods Hum Nutr. 2009;64(4):297-302. doi: 10.1007/s11130-009-0140-1

45. Schieber A,StintzingFC, Carla R. By-products of plant food processing as a source of functional compounds-Recent developments. Trends in Food Science and Technology. 2001;12(11):401-413.

46. Sharma G, Prakash D, Gupta C. Phytochemicals of Nutraceutical Importance: Do they defend against diseases? CABI International Publishers, UK; 2014. p.1-19.

47. Sharma G, Vivek, Gupta AK, Ganjewala D, Gupta C, Prakash D. Phytochemical composition, Antioxidant and Antibacterial potential of Underutilized parts of some fruits. International Food Research Journal 2017;24(3):1167-1173.

48. Shrikhande AJ. Wine by products with health benefits. Food Research International Journal. 2000;33(6):469-474.

49. Shui G, Leong LP. Residue from star fruit as valuable source for functional food ingredients and antioxidant nutraceuticals. Food Chemistry. 2006;97(2):277-284.

50. Singh N, Rajini PS. Free radical scavenging activity of an aqueous extract of potato peel. Food Chemistry. 2004;85(4):611-616.

51. Singh RP, Murthy KNC, Jayaprakasha GK. Studies on the antioxidant activity of pomegranate (Punica granatum) peel and seed extracts using in vitro models. J Agric Food Chem. 2002;50(1):81-86.
52. Someya S, Yoshiki Y, Okubo K. Antioxidant compounds from bananas (Musa cavendish). Food Chemistry. 2002;79(3):351-354.

53. Sonja D, Jasna CB, Gordana C. By-Products of fruits processing as a source of phytochemicals. Chemical Industry \& Chemical Engineering Quarterly. 2009;15(4):191-202.

54. Sultan S, Huma N, Butt MS, Aleem M, Abbas M. Therapeutic potential of dairy bioactive peptides: A Contemporary Perspectives. Crit Rev Food Sci Nutr. 2016;1-11. doi: 10.1080/10408398.2015.1136590

55. Thibault JF, Ralet MC. Physico-chemical properties of pectins in the cell walls and after extraction. Advances in Pectin and Pectinase Research. 2003;91-105.

56. Upadhyay A, Lama JP, Tawata S. Utilization of Pineapple Waste: A Review. Journal of Food Science \& Technology 2010;6:10-18.

57. Wang F, Li J, Jiang Y. Polysaccharides from mulberry leaf in relation to their antioxidant activity and antibacterial ability. Journal of Food Process Engineering. 2010;33:39-50.

58. World Resources Institute. Food Loss and Waste Accounting and Reporting Standard. Washington, DC. 2016.

59. Xu GH, Chen JC, Liu DH, Zhang YH, Jiang P, Ye XQ. Minerals, phenolic compounds, and antioxidant capacity of citrus peel extract by hot water. J Food Sci. 2008;73(1):C11-18. doi: 10.1111/j.17503841.2007.00546.x 